\title{
How valid is the clinical diagnosis of Parkinson's disease in the community?
}

\author{
A Schrag, Y Ben-Shlomo, N Quinn
}

J Neurol Neurosurg Psychiatry 2002;73:529-534

See end of article for authors' affiliations

.....................

Correspondence to: Professor N P Quinn Sobell Department of Motor Neuroscience and Movement Disorders, Institute of Neurology, Queen Square, London WCIN 3BG, UK n.quinn@ion.ucl.ac.uk

Received 13 March 2002 In revised form 7 August 2002

Accepted 20 August 2002
Background: Many patients diagnosed with Parkinson's disease are later found to have an erroneous diagnosis, often only when they come to necropsy; conversely, many patients with Parkinson's disease in the community remain undiagnosed.

Objective: To assess the validity of a clinical diagnosis of parkinsonism in the general population according to strict published criteria.

Methods: As part of a population based study on the prevalence of Parkinson's disease in London, all patients were identified with a diagnosis of parkinsonism, tremor with onset over age 50 years, or who had ever received antiparkinsonian drugs. All patients who agreed to participate were diagnosed according to strict clinical diagnostic criteria, after a detailed neurological interview and examination and discussion of the findings with examination of their video recordings. Follow up information was obtained over a period of at least one year, and atypical cases were reviewed at the end of the study. Results: A diagnosis of probable Parkinson's disease was confirmed in $83 \%$ of patients with this diagnosis, including three $(2 \%)$ in whom atypical features were found that were insufficient to discard a diagnosis of Parkinson's disease. Two additional patients $(2 \%)$ were found to have possible Parkinson's disease. However, in 15\% of patients the diagnosis was unequivocally rejected. Conversely, 13 patients who had previously not been diagnosed with Parkinson's disease (19\%) were found to have this disorder.

Conclusions: At least $15 \%$ of patients with a diagnosis of Parkinson's disease in the population do not fulfil strict clinical criteria for the disease, and approximately $20 \%$ of patients with Parkinson's disease who have already come to medical attention have not been diagnosed as such.
$\mathrm{P}$ athological examination of the brains of patients with a clinical diagnosis of Parkinson's disease shows a different diagnosis in up to $35 \%$ of cases. ${ }^{1-5}$ Retrospective application of strict clinical criteria increases the likelihood of correct diagnosis, ${ }^{2}$ although a proportion of patients who do not have Parkinson's disease still fulfil clinical criteria for the disease in such an analysis. Conversely, patients with Parkinson's disease may be misdiagnosed as having other parkinsonian disorders, ${ }^{4}$ or not be recognised to have parkinsonian features. ${ }^{6}$ In the absence of a readily available biological marker for Parkinson's disease, the only certain means of diagnosis at present is the finding of depletion of brain stem pigmented neurones with Lewy bodies at necropsy. However, pathological examination is only possible in a minority of patients with parkinsonism, and pathological case series are prone to referral bias and probably overrepresent atypical cases.

We aimed to identify as many patients as possible who may have Parkinson's disease from an unselected primary care population and compare their existing diagnosis with expert diagnosis using strict published criteria and follow up. ${ }^{8}$ In this way we could quantify the sensitivity and specificity of the pre-existing diagnosis, compare this for different types of clinicians, and determine which features were more likely to be associated with probable Parkinson's disease.

\section{METHODS}

\section{Patient ascertainment}

The methods of patient ascertainment and study design were reported previously. ${ }^{8}$ In brief, the records of 15 general practices in the area of London (14 in London and one in Kent) were screened for patients. As the health care system in the United Kingdom is organised locally, the population of a general practice is representative of the surrounding area. In addition, the general practitioner acts as a "gatekeeper" of the NHS, so that patients are only referred to specialists by their general practitioners. The computerised records were screened in three ways: first, we identified all patients with a current or previous mention of Parkinson's disease or another parkinsonian disorder; second, we identified all patients who had been prescribed an antiparkinsonian drug on prevalence day or at any time in the past; and third, we identified all patients in whom a tremor had been noted at any time after the age of 50 years. This multiple approach was taken to include as many patients with parkinsonism as possible in the screening, including patients who had not been coded as having parkinsonism. Patients with tremor beginning before the age of 50 were censored in order to exclude those with benign essential tremor, and because the risk of missing patients with parkinsonism presenting at a young age with only tremor and without other neurological signs was considered minimal in this cross sectional study.

The computerised and hard copy records of all eligible patients were reviewed. Patients were excluded from further evaluation for the following reasons: if they had used antiparkinsonian drugs for other indications (for example, bromocriptine for pituitary adenoma or anticholinergic drugs in association with dopamine antagonists for psychotic disorders); if they had another known cause of tremor (for example, hyperthyroidism); or if they were miscoded. Patients whose onset of parkinsonian symptoms was within six months of at least six months of treatment with dopamine receptor blocking drugs and patients who had developed dementia before the onset of parkinsonism were also excluded.

The remaining patients were contacted through their general practitioners (in all but one practice) and invited to be 
Table 1 Initial and final diagnosis of patients seen in this population based study $(\mathrm{n}=202)$

\begin{tabular}{|c|c|c|c|c|c|c|c|}
\hline \multirow[b]{2}{*}{ Final diagnosis } & \multicolumn{6}{|c|}{ Initial diagnosis } & \multirow[b]{2}{*}{ Total } \\
\hline & $\begin{array}{l}\text { Parkinson's } \\
\text { disease }\end{array}$ & $\begin{array}{l}\text { Atypical } \\
\text { parkinsonism }\end{array}$ & $\begin{array}{l}\text { Vascular } \\
\text { parkinsonism }\end{array}$ & $\begin{array}{l}\text { Non-parkinsonian } \\
\text { tremor }\end{array}$ & $\begin{array}{l}\text { Other patients on } \\
\text { antiparkinsonian drugs }\end{array}$ & $\begin{array}{l}\text { Diagnostic } \\
\text { referral }\end{array}$ & \\
\hline Probable Parkinson's disease & 109 & 1 & 1 & 9 & 2 & 2 & $124(61.4 \%)$ \\
\hline Possible Parkinson's disease & 2 & 0 & 0 & 2 & 0 & 0 & $4(2.0 \%)$ \\
\hline Multiple system atrophy & 3 & 0 & 0 & 0 & 0 & 0 & $3(1.5 \%)$ \\
\hline Progressive supranuclear palsy & 4 & 0 & 1 & 0 & 1 & 0 & $6(3.0 \%)$ \\
\hline Vascular parkinsonism & 6 & 0 & 0 & 1 & 5 & 0 & $12(5.9 \%)$ \\
\hline Non-parkinsonian tremor & 4 & 0 & 0 & 41 & 1 & 0 & $46(22.8 \%)$ \\
\hline Other & 3 & 0 & 0 & 3 & 1 & 0 & $7(3.5 \%)$ \\
\hline Total & $131(64.9 \%)$ & $1(0.5 \%)$ & $2(1.0 \%)$ & 56 (27.7\%) & $10(5.0 \%)$ & $2(1.0 \%)$ & $202(100 \%)$ \\
\hline
\end{tabular}

seen at the National Hospital for Neurology and Neurosurgery, at their general practitioner's surgery, or at home.

Approval for the study was given by the joint research ethics committee of the National Hospital for Neurology and Neurosurgery and the Institute of Neurology, London.

\section{Diagnosis}

All patients who agreed to participate had a general and neurological interview and examination, and a questionnaire-designed to detect signs and symptoms of typical and atypical parkinsonian disorders-was completed by one of the investigators (AS). If the subject agreed to this, a video recording of the neurological signs was made. The diagnosis was made according to published criteria (see below) after review and discussion of each subject and examination of their videotape. All patients in whom a diagnosis of parkinsonism was made received a questionnaire on atypical features and symptoms of progression (for example, development of falls) every three months for a period of one year. In addition, the general practitioners were asked about any new, atypical features in the eligible patients at the end of the study. Patients who had atypical features at the first visit, or developed them during follow up, and those in whom a probable diagnosis could not be made at the first visit, were reviewed after at least one year.

\section{Diagnostic criteria}

Parkinsonism was diagnosed if bradykinesia and at least one other cardinal sign (resting tremor, rigidity, or postural instability) were present. Parkinson's disease was diagnosed according to the UK Parkinson's disease society brain bank criteria" with the exception that an isolated positive Babinski sign, for instance in an elderly patient with otherwise typical Parkinson's disease, was not considered to invalidate the diagnosis. In addition, patients with isolated classical resting tremor only were diagnosed as having "possible Parkinson's disease." Multiple system atrophy (probable and possible) was diagnosed according to Quinn, ${ }^{10}$ and progressive supranuclear palsy (probable and possible) according to criteria proposed by the National Institute of Neurological Disorders and Stroke (NINDS) and the Society for PSP (SPSP). ${ }^{11}$

Vascular parkinsonism was diagnosed when there was the presence of at least two of the following: a history of previous strokes, abrupt onset with stepwise progression, hypertension, a wide based gait with small steps, cognitive decline, and pseudobulbar or pyramidal signs.

Drug induced parkinsonism was diagnosed if the onset of parkinsonian symptoms was within six months of at least six months of treatment with dopamine receptor blocking drugs, and still present on prevalence day.

The diagnosis of non-parkinsonian tremor included various types of tremor such as essential, dystonic, and enhanced physiological tremor; the distinction of these syndromes is still a matter of debate. ${ }^{12}$

\section{Data analysis}

Only patients who were seen and were resident in the study area on prevalence day (1 July 1997) were included. Sensitivity, specificity, and positive and negative predictive values were calculated using standard formulae (see appendix). We calculated these variables for the overall sample excluding the patients referred for diagnosis (both of whom had Parkinson's disease), as well as separately for a specialist (neurologist or geriatrician) or non-specialist diagnosis. Group differences were analysed by the Mann-Whitney test. Categorical data were compared with the $\chi^{2}$ test, and Fisher's exact test if appropriate.

\section{RESULTS}

We identified 241 patients using our screening criteria and 202 patients agreed to be reviewed (participation rate $84 \%$ ), the remaining patients refusing to take part in the study. Patients who declined were slightly older than those who participated $(p<0.05)$, but there was no significant sex difference. They did not differ with regard to the percentage of patients who had a previous diagnosis of Parkinson's disease.

Among the 202 participants, 134 (66\%) had received a diagnosis of parkinsonism (131 of Parkinson's disease, one of atypical parkinsonism, and two of vascular parkinsonism). Ten additional patients $(5 \%)$ had been prescribed antiparkinsonian drugs for parkinsonian symptoms without a further specified diagnosis. Fifty six patients $(28 \%)$ had been noted to have a tremor with onset after the age of 50 without having been suspected of having parkinsonism, and two patients ( $1 \%$ ) were referred to us for diagnostic purposes without a previous diagnosis (table 1).

\section{Patients with a previous diagnosis of Parkinson's disease}

The diagnosis of probable Parkinson's disease was confirmed in 109 of the 131 patients with this diagnosis (83\%), including three $(2 \%)$ in whom atypical features were found but were insufficient to invalidate the diagnosis of Parkinson's disease (table 2). Two additional patients $(2 \%)$ were found to have

Table 2 Patients with an initial diagnosis of Parkinson's disease $(n=131)$

\begin{tabular}{lllll}
\hline Final diagnosis & $\mathrm{n}$ & $\%$ & $\begin{array}{l}\text { Mean age } \\
\text { (years) }\end{array}$ & $\begin{array}{l}\text { Seen by } \\
\text { specialist (\%) }\end{array}$ \\
\hline Probable Parkinson's disease & 109 & 83.3 & 71.6 & $85(78 \%)$ \\
Possible Parkinson's disease & 2 & 1.5 & 81.5 & $1(50 \%)$ \\
Multiple system atrophy & 3 & 2.3 & 78.3 & $1(33 \%)$ \\
Progressive supranuclear palsy & 4 & 3.1 & 71.8 & $2(50 \%)$ \\
Vascular parkinsonism & 6 & 4.6 & 82.5 & $5(83 \%)$ \\
Non-parkinsonian tremor & 4 & 3.1 & 65.5 & $3(75 \%)$ \\
Other & 3 & 2.3 & 84.7 & 0 \\
\hline
\end{tabular}


Table 3 Patients with a final diagnosis of probable Parkinson's disease $(n=124)$

\begin{tabular}{lllll}
\hline Initial diagnosis & $\mathrm{n}$ & $\%$ & $\begin{array}{l}\text { Mean age } \\
\text { (years) }\end{array}$ & $\begin{array}{l}\text { Seen by } \\
\text { specialist (\%) }\end{array}$ \\
\hline Parkinson's disease & 109 & 87.9 & 72 & $85(78 \%)$ \\
Atypical parkinsonism & 1 & 0.8 & 55 & $1(100 \%)$ \\
Vascular parkinsonism & 1 & 0.8 & 69 & $1(100 \%)$ \\
Non-parkinsonian tremor & 9 & 7.3 & 74 & $3(33 \%)$ \\
On antiparkinsonian drugs & 2 & 1.6 & 84.5 & 0 \\
Referred for diagnosis & 2 & 1.6 & 82.5 & $2(100 \%)$ \\
\hline
\end{tabular}

possible Parkinson's disease. However, in 20 of the 131 patients $(15 \%)$ the diagnosis of Parkinson's disease was unequivocally rejected (table 2 ). The alternative diagnoses were non-parkinsonian tremor in four patients (3\%), vascular parkinsonism in six $(5 \%)$, progressive supranuclear palsy in four (3\%; probable in three and possible in one), and multiple system atrophy in three $(2 \%$; probable in two and possible in one). Two patients received a diagnosis of idiopathic torsion dystonia, and one of dementia without parkinsonism. When only those patients who had seen a specialist at some point in the past ( 97 patients, $74 \%$ ) were considered, the diagnosis was changed from Parkinson's disease to a different diagnosis in $11 \%$.

\section{Patients with a previous diagnosis other than Parkinson's disease}

Among all patients seen, two were referred for diagnostic purposes without a previous diagnosis, and 69 of 202 patients (34\%) had a previous diagnosis other than Parkinson's disease (tables 3 and 4). Among these, 56 patients (81\%) had been given a diagnosis of non-parkinsonian tremor, two $(3 \%)$ of vascular parkinsonism, one ( $1 \%$ ) of atypical parkinsonism, and $10(14 \%)$ had been prescribed an antiparkinsonian drug for parkinsonian features without a specific diagnosis (table 1). Thirteen of the 69 patients with different diagnoses (19\%) and the two patients referred for diagnostic purposes fulfilled strict clinical criteria for Parkinson's disease (table 1). In two additional patients who had a previous diagnosis of nonparkinsonian tremor, a diagnosis of "possible Parkinson's disease" was made (3\%). If only patients who had at some point in the past seen a specialist ( 26 of 69 patients, $38 \%$ ) were considered, the diagnosis was changed to probable Parkinson's disease in five $(19 \%)$ and to possible Parkinson's disease in one $(4 \%)$.

\section{Sensitivity, specificity, and predictive value of a previous diagnosis of Parkinson's disease}

Of 126 patients with a pre-existing clinical diagnosis of probable and possible Parkinson's disease in the overall sample (patients identified through an initial diagnosis of parkinsonism, a record of tremor with onset after age 50, or identified through previous prescription of antiparkinsonian drugs, excluding those who were referred for diagnosis), 111 were confirmed as having Parkinson's disease, resulting in a sensitivity of $88.1 \%$ (95\% confidence interval, $81.1 \%$ to $93.2 \%$ ); similarly, it was confirmed that 54 of 74 patients did not have Parkinson's disease, resulting in a specificity of $73.0 \%(61.3 \%$ to $82.6 \%$ ). The positive and negative predictive values of a previous clinical diagnosis of Parkinson's disease were $84.7 \%$ ( $77.4 \%$ to $90.4 \%$ ) (111 of 131 patients) and $78.3 \%$ (66.7\% to $87.3 \%$ ) (54 of 69 patients). In other words, in $85 \%$ of patients with a previous diagnosis of Parkinson's disease this diagnosis was confirmed, and $78 \%$ of patients with a diagnosis other than Parkinson's disease did not have the disease (table 4).

When this was broken down by a specialist or other doctor diagnosis, the diagnostic validity was as follows. Neurologists and geriatricians had a sensitivity and specificity of $93.5 \%$ (86.3\% to $97.6 \%$ ) (86 of 92 patients) and $64.5 \%$ (45.4\% to $80.8 \%$ ) (20 of 31 patients), respectively, compared with $73.5 \%$ (55.6\% to $87.1 \%$ ) (25 of 34 patients) and $79.1 \%(64.0 \%$ to $90.0 \%$ ) (34 of 43 patients) for non-specialists. The positive predictive values were greater for specialists $(88.7 \% ; 80.6 \%$ to $94.2 \%)$ than for other doctors $(73.5 \% ; 55.6 \%$ to $87.1 \%)$, but the negative predictive values were equivalent (specialist $76.9 \%$ $(56.4 \%$ to $91.0 \%) v$ non-specialist $79.1 \%(64.0 \%$ to $90.0 \%)$ ).

\section{Likelihood of referral according to final diagnosis}

Overall, 74\% of all cases with a diagnosis of Parkinson's disease had been seen by a specialist. However, when these cases were classified by final diagnosis (table 2), it was observed that, paradoxically, fewer cases with atypical disease (54.5\%) had been seen by a specialist compared with those with classical Parkinson's disease $(78.0 \%$ ) (difference in proportions $23.4 \%$ ( $1.2 \%$ to $45.6 \%)$; $p=0.02)$.

\section{Comparison of patients in whom a diagnosis of Parkinson's disease was maintained or rejected}

Patients in whom a diagnosis of Parkinson's disease was confirmed had more severe disease as measured by the Hoehn and Yahr stage $(p<0.05)$, more often had a tremor at rest $(p<0.01)$ or a classical pill rolling tremor $(p<0.01)$, and more often reported a good initial and sustained response to levodopa (both $\mathrm{p}<0.001$ ) than those in whom it was rejected.

Patients in whom the diagnosis was changed to nonparkinsonian tremor had no other parkinsonian features such as rigidity, bradykinesia, hypomimia, or monotonous speech. They also reported falls significantly less frequently $(\mathrm{p}<0.01)$ and had higher mini-mental state scores $(\mathrm{p}<0.05)$. Those in whom the diagnosis was changed to atypical parkinsonism (multiple system atrophy or progressive supranuclear palsy) had more severe akinesia $(p<0.05)$, rigidity $(p<0.01)$, and postural instability $(\mathrm{p}<0.05)$, less commonly reported an initially or currently good response to levodopa (both $\mathrm{p}<0.01)$, but more often had incontinence $(\mathrm{p}<0.01)$ and additional features incompatible with Parkinson's disease. Those in whom the diagnosis was changed to vascular parkinsonism were older than those in whom a diagnosis of Parkinson's disease was confirmed $(\mathrm{p}<0.05)$, had a larger number

Table 4 Sensitivity, specificity, and predictive values for the overall sample* and by type of clinician

\begin{tabular}{|c|c|c|c|c|c|c|c|c|c|c|c|}
\hline \multirow[b]{3}{*}{$\begin{array}{l}\text { Previous } \\
\text { diagnosis }\end{array}$} & \multicolumn{4}{|l|}{ Overall } & \multicolumn{4}{|l|}{ Specialists } & \multicolumn{3}{|c|}{ Non-specialists } \\
\hline & \multicolumn{2}{|c|}{ Final diagnosis } & \multirow[b]{2}{*}{ Total } & \multirow[b]{2}{*}{$\begin{array}{l}\text { Previous } \\
\text { diagnosis }\end{array}$} & \multicolumn{2}{|c|}{ Final diagnosis } & \multirow[b]{2}{*}{ Total } & \multirow[b]{2}{*}{$\begin{array}{l}\text { Previous } \\
\text { diagnosis }\end{array}$} & \multicolumn{2}{|c|}{ Final diagnosis } & \multirow[b]{2}{*}{ Tota } \\
\hline & $\begin{array}{l}\text { Probable or } \\
\text { possible PD }\end{array}$ & Not PD & & & $\begin{array}{l}\text { Probable or } \\
\text { possible PD }\end{array}$ & Not PD & & & $\begin{array}{l}\text { Probable or } \\
\text { possible PD }\end{array}$ & Not PD & \\
\hline$P D$ & 111 & 20 & 131 & PD & 86 & 11 & 97 & PD & 25 & 9 & 34 \\
\hline Not PD & 15 & 54 & 69 & Not PD & 6 & 20 & 26 & Not PD & 9 & 34 & 43 \\
\hline Total & 126 & 74 & 200 & Total & 92 & 31 & 123 & Total & 34 & 43 & 77 \\
\hline
\end{tabular}

*This excludes two patients without a pre-existing diagnosis who were referred for an opinion. PD, Parkinson's disease. 
of smoking years $(\mathrm{p}<0.01)$, more often had gait difficulties as their first complaint $(p<0.05)$, and had more severe postural instability $(p<0.001)$; they never had a rest tremor.

\section{Patients in whom a diagnosis of Parkinson's disease was or was not previously made}

Patients in whom a diagnosis of Parkinson's disease was previously made had a longer disease duration $(p<0.05)$ and greater disease severity $(\mathrm{p}<0.01)$, with more severe akinesia $(\mathrm{p}<0.01)$, postural instability, and rigidity (both $\mathrm{p}<0.001)$ than those in whom the diagnosis was not made before. They were also more likely to be depressed $(p<0.05)$, to have experienced dyskinesias $(\mathrm{p}<0.05)$, and to live alone or with their family than in a nursing home $(\mathrm{p}<0.05)$.

\section{DISCUSSION}

The results of this study, on a community level, correspond with results from pathological studies indicating that Parkinson's disease is often confused with other disorders. The main areas of diagnostic difficulty concern the distinction from other types of isolated, late onset tremor, vascular parkinsonism, and atypical types of parkinsonism, which are often mistakenly diagnosed as Parkinson's disease. On the other hand, patients with Parkinson's disease are sometimes not recognised as having this disorder, particularly those with mild disease or a relatively isolated tremor.

The rate of underdiagnosis is likely to be even higher, as we included only patients who had already come to medical attention with tremor or parkinsonian features. Some patients not meeting our screening criteria, particularly elderly people with akinetic-rigid parkinsonism without tremor, would have been missed in this study if postural instability and other parkinsonian features were attributed to old age. In door to door studies on the prevalence of Parkinson's disease, the proportion of previously undiagnosed patients has ranged from $12 \%$ to $60 \%{ }^{6}{ }^{63}$ We employed wide screening criteria in this study in order to detect as many patients with a parkinsonian syndrome as feasible. For this reason, and owing to the comparatively easy access to and high density of neurologists in the study area of London, we believe that our rate of underdiagnosis is relatively low and comparable to that of $12 \%$ found in a recent door to door study with otherwise similar study design in the Netherlands. ${ }^{13}$

As may have been expected, Parkinson's disease was more often recognised in patients with greater disease severity, who had had the disease for longer, and had already developed complications such as depression and dyskinesias, and were more likely to live alone or with their family than in a nursing home.

The accuracy of the diagnosis of Parkinson's disease has been conspicuously poor in the few studies assessing patients with this clinical diagnosis. When compared to pathological diagnosis, the rate of false positive clinical diagnosis of Parkinson's disease in life was $24 \%$ in one study of 100 patients. ${ }^{2}$ This rate improved to $18 \%$ when strict clinical criteria were used retrospectively. In a second later study, the same group reported that the rate of misdiagnosis in a series of 100 patients who had died with a diagnosis of Parkinson's disease had fallen to $16 \%^{3}$ and later to $10 \% .^{5}$ In another study of 43 patients with a clinical diagnosis of Parkinson's disease, the rate of correct diagnosis at the initial visit was only $65 \%$ compared with the pathological diagnosis, but rose to $76 \%$ at the final visit. ' Samples from brain banks and specialist clinics are, however, likely to overrepresent atypical disorders owing to the referral bias inherent in such samples. ${ }^{7}$ Nevertheless, prevalence studies of Parkinson's disease which have employed strict clinical diagnostic criteria have also yielded rates of false positive diagnoses ranging from $14.5 \%$ to $44 \%$, the commonest alternative diagnoses being essential tremor, vascular parkinsonism, dementia, and drug induced parkinsonism..$^{14-16}$ In a more recent population based study ${ }^{17}$ assessing the accuracy of diagnosis in patients with presumed Parkinson's disease, using the same criteria for diagnosis ${ }^{9}$ as in the present study, only $53 \%$ of 402 patients were clinically confirmed to have Parkinson's disease. Patients with drug induced parkinsonism and dementia before the onset of parkinsonism, who were excluded in our study, constituted $12 \%$ and $4 \%$, respectively, and patients who did not fulfil full criteria for probable Parkinson's disease, which would have been labelled "possible Parkinson's disease" in our study, were included in the group of "unspecified parkinsonism." Thus if these cases are excluded, the rate of false positive diagnosis was similar in the two studies. However, in the study cited, ${ }^{17}$ the diagnosis was more frequently changed to essential tremor (12\%), which was the final diagnosis in only $3 \%$ of patients previously diagnosed as Parkinson's disease in our study. A possible explanation for this finding may be earlier referral to neurology clinics and earlier diagnosis in this study owing to the high density and relatively easy access to neurology departments in London.

We found that a false positive diagnosis of Parkinson's disease was made predominantly in patients with other neurodegenerative causes of parkinsonism, such as multiple system atrophy and progressive supranuclear palsy, and in patients with vascular parkinsonism. This is in agreement with pathological studies, where approximately $6 \%$ of incorrectly diagnosed patients had progressive supranuclear palsy, 5-9\% had multiple system atrophy, and 3\% had vascular parkinsonism. ${ }^{12}$ As we excluded patients with dementia who later developed parkinsonism, the rate of false positive diagnosis of Parkinson's disease in patients with Alzheimer's disease, which represented $2-6 \%$ in pathological studies, was smaller in our sample. Likewise, patients who had used neuroleptic drugs within six months of the onset of symptoms were excluded a priori, and the rate of misdiagnosis of drug induced parkinsonism was therefore lower. The accuracy of diagnosis of Parkinson's disease in the general population in this study is thus very similar to the pattern of diagnostic difficulties in the clinicopathological studies.

In order to improve the accuracy of diagnosis, this study was specifically designed to detect atypical features (which is more problematic in a retrospective analysis of case notes of patients coming to necropsy examination). We therefore believe that the accuracy of our clinical diagnosis is relatively high. However, some patients do not develop or display features permitting unequivocal diagnosis of atypical disease during life. When using the same diagnostic criteria that were applied in this study, Hughes et al still found an $18 \%$ rate of misdiagnosis of Parkinson's disease at necropsy. ${ }^{2}$ Although in a later study by the same group the rate of misdiagnosis was lower, ${ }^{35}$ we therefore estimate that at least another $10 \%$ of the patients diagnosed with Parkinson's disease in our study may nevertheless have a different disorder.

Neurologists and geriatricians performed better than non-specialists, despite the fact that they were probably more likely to see more difficult cases. Our figures for sensitivity and specificity for both groups of clinicians are slightly unfair as referral to a specialist in itself may reflect the general practitioners' uncertainty about the diagnosis, and as we had the benefit of making the diagnosis after some time had elapsed. In this way we may have been able to detect additional features that were atypical but not present when the initial diagnosis was made. This highlights the importance of reassessment of patients, even after a diagnosis has been made. Non-specialists performed reasonably well in this study. However, it should be noted that we may have overestimated the specificity of their diagnosis as it is possible that additional patients with Parkinson's disease who had presented to their general practitioners were not detected by our methods. In this case the "true" false negative rate would be higher than reported. 
Table 5 Helpful diagnostic hints

\begin{tabular}{|c|c|c|c|}
\hline Parkinson's disease & Non-parkinsonian tremor & Vascular parkinsonism & Atypical parkinsonism \\
\hline $\begin{array}{l}\text { - Classical pill rolling rest tremor } \\
\text { - Good and sustained response to } \\
\text { levodopa }\end{array}$ & $\begin{array}{l}\text { - Lack of rigidity } \\
\text { - Lack of bradykinesia } \\
\text { - Lack of other parkinsonian } \\
\text { features, eg hypomimia, } \\
\text { monotonous speech, } \\
\text { abnormalities of gait or posture } \\
\\
\text { - Intact cognition } \\
\text { - Lack of falls }\end{array}$ & $\begin{array}{l}\text { - Older age } \\
\text { - Hypertension } \\
\text { - Longer history of smoking } \\
\text { - History of previous strokes } \\
\text { - Abrupt onset with stepwise progression; } \\
\text { more frequent gait difficulties; more } \\
\text { - Wevere postural instability } \\
\text { - Less frequent tremor; no rest tremor; } \\
\text { cognitive decline; pseudobulbar } \\
\text { signs; pyramidal signs }\end{array}$ & $\begin{array}{l}\text { - More severe parkinsonian syndrome } \\
\text { - More rapid evolution } \\
\text { - Greater postural instability } \\
\text { - Poor initial or current response to levodopa } \\
\text { - Incontinence } \\
\text { - Additional features incompatible with PD }\end{array}$ \\
\hline
\end{tabular}

PD, Parkinson's disease

Some have argued that all newly presenting cases with a movement disorder should initially be referred to a neurologist or specialist with an interest in movement disorders. This may be an idealistic goal, but in the United Kingdom long outpatient waiting lists make it difficult to achieve. An alternative pragmatic strategy is that patients presenting in general practice with classical Parkinson's disease and a good therapeutic response to levodopa can initially be managed at a primary care level, but that young onset disease or cases with any atypical features should always be referred to a specialist. Our data, however, revealed the opposite trend, in that atypical patients were if anything less likely to be referred. General practitioners should be given better guidelines and further training in when to refer cases to enhance patient care. We have listed the features that were found helpful in the differential diagnosis of Parkinson's disease in table 5.

The results of this study may not be completely transferable to other communities. It was conducted in the London area and the characteristics of this study population, the participating practices, and the health care system in the United Kingdom may have influenced the results to some degree. Differences between practices with regard to computerised records, which allow more ready identification especially of mild symptoms, differences in practice size and age distribution, and in access to specialised services, and the practices and attitudes of general practitioners and patients might have influenced the results. Thus, in this study only practices with computerised records were included-mainly inner city practices-and the age range (table 6) was relatively young, representative of the London population. It is thus possible that a similar study in a different population and health care system might have yielded somewhat different results. However, the similarity between results from this study and others in different populations supports the assumption that the validity of a diagnosis of Parkinson's disease follows a similar pattern in different communities, perhaps reflecting the universal difficulties of making a correct diagnosis of this disorder.

Table 6 Study population by age group and sex

\begin{tabular}{llll}
\hline Age (years) & Men & Women & Total \\
\hline $0-29$ & 22829 & 25435 & 48267 \\
$30-39$ & 13214 & 12909 & 12123 \\
$40-49$ & 8815 & 7774 & 16589 \\
$50-59$ & 6168 & 5737 & 11923 \\
$60-69$ & 4291 & 4191 & 8482 \\
$70-79$ & 2810 & 3540 & 6350 \\
$>80$ & 1266 & 2608 & 3874 \\
\hline
\end{tabular}

\section{Conclusions}

At least $15 \%$ of patients with a diagnosis of Parkinson's disease in the population do not fulfil strict clinical criteria for the disease, and approximately $20 \%$ of patients who do have the disease and who have already come to medical attention are not diagnosed as such. The application of strict clinical criteria helps to identify patients with idiopathic Parkinson's disease, progressive supranuclear palsy, and multiple system atrophy, and aids their differentiation from vascular parkinsonism, drug induced parkinsonism, and non-parkinsonian tremor.

\section{ACKNOWLEDGEMENT}

This study was made possible by a grant from SmithKline Beecham Pharmaceuticals.

\section{APPENDIX}

Definition of terms used in the analysis

\begin{tabular}{|c|c|c|}
\hline \multirow[b]{2}{*}{ Previous diagnosis } & \multicolumn{2}{|c|}{ Final diagnosis } \\
\hline & $\begin{array}{l}\text { Parkinson's } \\
\text { disease }\end{array}$ & $\begin{array}{l}\text { Not Parkinson's } \\
\text { disease }\end{array}$ \\
\hline Parkinson's disease & A & B \\
\hline Not Parkinson's disease & C & D \\
\hline
\end{tabular}

Sensitivity: Proportion of patients with a final diagnosis of Parkinson's disease who were previously diagnosed as having Parkinson's disease: $\mathrm{A} /(\mathrm{A}+\mathrm{C})$.

Specificity: Proportion of patients without a final diagnosis of Parkinson's disease who were previously diagnosed as not having Parkinson's disease: $\mathrm{D} /(\mathrm{D}+\mathrm{B})$

Positive predictive value: Proportion of patients with a previous diagnosis of Parkinson's disease who received a final diagnosis of Parkinson's disease: $\mathrm{A} /(\mathrm{A}+\mathrm{B})$

Negative predictive value: Proportion of patients with a previous diagnosis of not having Parkinson's disease who received a final diagnosis of not having Parkinson's disease: $D /(D+C)$.

Authors' affiliations

A Schrag, N Quinn, Sobell Department of Motor Neurosciences and Movement Disorders, Institute of Neurology, London WC1, UK Y Ben-Shlomo, Department of Social Medicine, University of Bristol, Bristol, UK

Competing interests: none declared 


\section{REFERENCES}

1 Rajput AH, Rozdilsky B, Rajput A. Accuracy of clinical diagnosis in parkinsonism - a prospective study. Can J Neurol Sci 1991;18:275-8.

2 Hughes AJ, Ben-Shlomo Y, Daniel SE, et al. What features improve the accuracy of clinical diagnosis in Parkinson's disease: a clinicopathologic study. Neurology 1992;42:1142-6.

3 Ansorge O, Lees AV, Daniel SE. Update on the accuracy of clinical diagnosis of idiopathic Parkinson's disease. Mov Disord 1997;12(suppl 1):96.

4 Litvan I, Maclntyre A, Goetz CG, et al. Accuracy of the clinical diagnoses of Lewy body disease, Parkinson disease, and dementia with Lewy bodies: a clinicopathologic study. Arch Neurol 1998:55:969-78.

5 Hughes AJ, Daniel SE, Lees AJ. Improved accuracy of clinical diagnosis of Lewy body Parkinson's disease. Neurology 2001;57:1497-9.

6 Schoenberg BS, Anderson DW, Haerer AF. Prevalence of Parkinson's disease in the biracial population of Copiah County, Mississippi. Neurology 1985;35:841-5.

7 Maraganore DM, Anderson DW, Bower JH, et al. Potential bias in autopsy series of Parkinson's disease and related disorders [abstract]. Neurology 1998;50:A98.

8 Schrag A, Ben-Shlomo Y, Quinn NP. Prevalence of progressive supranuclear palsy and multiple system atrophy: a cross-sectional study. Lancet 1999;354:1771-5.
9 Gibb WR, Lees AJ. The significance of the Lewy body in the diagnosis of idiopathic Parkinson's disease. Neuropathol Appl Neurobiol 1989;15:27-44

10 Quinn N. Multiple system atrophy - the nature of the beast. J Neurol Neurosurg Psychiatry 1989;52(suppl):78-89.

11 Litvan I, Agid Y, Calne D, et al. Clinical research criteria for the diagnosis of progressive supranuclear palsy (Steele-Richardson-Olszewski syndrome): report of the NINDS-SPSP international workshop. Neurology 1996;47:1-9.

12 Chouinard S, Louis ED, Fahn S. Agreement among movement disorder specialists on the clinical diagnosis of essential tremor. Mov Disord 1997: 12:973-6.

13 De Rijk MC, Breteler MM, Graveland GA, et al. Prevalence of Parkinson's disease in the elderly: the Rotterdam Study. Neurology 1995;45:2143-6.

14 Marttila RJ, Rinne UK. Epidemiology of Parkinson's disease in Finland. Acta Neurol Scand 1976;53:81-102.

15 Sutcliffe RL, Meara JR. Parkinson's disease epidemiology in the Northampton District, England, 1992. Acta Neurol Scand 1995; 92:443-50.

16 Mutch WJ, Dingwall-Fordyce I, Downie AW, et al. Parkinson's disease in a Scottish city. BM 1986;292:534-6.

17 Meara J, Bhowmick BK, Hobson P. Accuracy of diagnosis in patients with presumed Parkinson's disease. Age Ageing 1999;28:99-102.

\section{NEUROLOGICAL PICTURE}

\section{Footprints of coagulopathy}

$\wedge$

68 year old man with chronic atrial fibrillation and a St Jude valve in mitral position discontinued warfarin several days prior to a coronary angiogram. Forty eight hours after restarting his warfarin while also on low molecular weight heparin and aspirin, he developed an acute motor aphasia and right hemiparesis. Computerised tomography (CT) in the emergency room revealed a large left frontal haemorrhage with multiple fluid blood levels (Fig 1). His INR was 2.4 on admission. Worsening in consciousness prompted emergent evacuation of the haematoma. Three months postoperatively he had only trace right sided weakness.

On CT, fluid blood levels in acute cerebral haematoma have a 59\% sensitivity and 98\% specificity for indicating underlying coagulopathy. ${ }^{1}$ The sharply demarcated interface represents a boundary between plasma and sedimented blood. ${ }^{2}$ Although all patients with intracerebral haemorrhage should routinely have PT, PTT, and platelet count performed, the fluid blood level on head CT may denote bleeding dyscrasias as the aetiology of haemorrhage. In fact, the CT scan may be available before the laboratory values return.

R D Ecker, E F M Wijdicks Departments of Neurosurgery and Neurology, Mayo Clinic and Foundation, Rochester, Minnesota, USA
Correspondence to: $\operatorname{Dr} R$ D Ecker, MD, Department of Neurological Surgery, Joseph 1-229, St. Mary's Hospital, 1216 Second Street, SW, Rochester, MN

\section{References} 55905, USA; ecker.rober@@mayo.edu

1 Pfleger M, Hardee E, Contant C, et al Sensitivity and specificity of fluid-blood levels
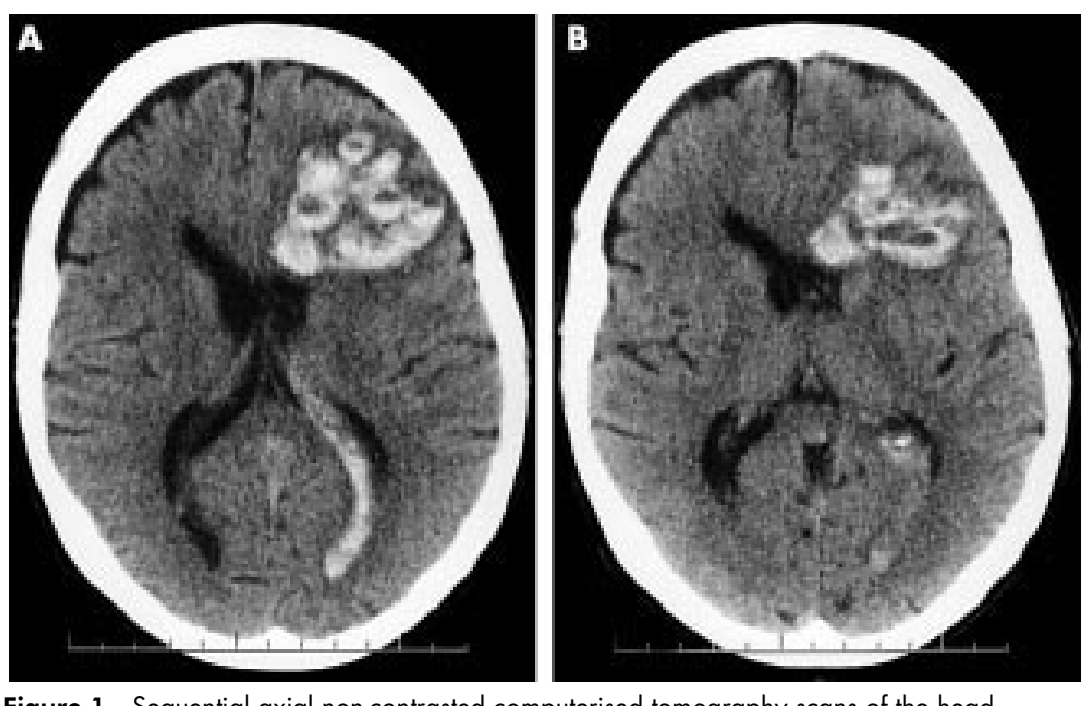

Figure 1 Sequential axial non-contrasted computerised tomography scans of the head demonstrating a large left frontal haemorrhage with multiple fluid blood levels and

intraventricular extension.

for coagulopathy in acute intracerebral hematomas. Am J Neuroradiol $1994 ; 15: 217-23$

2 Ichikawa K, Yanagihara C. Sedimentation level in acute intracerebral hematoma in a patient receiving anticoagulation therapy: an autopsy study. Neuroradiology 1998:40:380-2. 